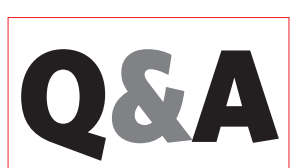

Lucila Ohno-Machado is the first chief of the new Division of Biomedical Informatics at the University of California, San Diego.

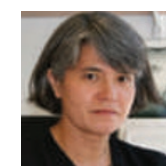

As a student, you were interested in both medicine and mathematics, how did you pursue the two?

At school, mathematics was my stronger subject and the one I enjoyed the most. I wanted to find a way to use mathematics in health care, initially with the idea of pursuing bioengineering. But growing up in Brazil I had to pursue a medical or an engineering degree and then find ways to combine my interests. I decided it would be easier to start with a medical degree and build on that.

\section{How did you navigate career opportunities in the emerging field of biomedical informatics?} You must be a risk taker. You can't possibly be too cautious when pursuing a career that is not yet seen as mainstream. My self-confidence helped me overcome the barriers created by people's inability to understand the potential of an emerging field. Twenty years ago, the United States had the right combination of programmes available and was open to interdisciplinary careers, so I came to Stanford University to get a $\mathrm{PhD}$ in medical information science.

\section{Will the new graduate} programme at the Division of Biomedical Informatics differ from other similar programmes?

Yes. Several programmes funded by the US National Institutes of Health do bioinformatics or medical informatics. But only a few of those do both, and even fewer provide trainees with access to clinical information systems. The San Diego programme will tightly combine bioinformatics and medical informatics while making use of data from the medical-centre hospitals, which will be available for our students and trainees as their laboratory.

\section{What drives your interest in finding patterns in clinical data?}

We are past the age when the experience of one clinician can lead to significant medical advances. We need to find practical ways to access all the data from a larger collection of patients being treated. If we can extract patterns that tell us what we are doing right and what we can do better in the clinic, it will help patients and health-care providers. For example, data registries exist for certain procedures, such as interventional cardiology, and these may be helpful to the clinician assessing the complications associated with a new device.

\section{What is the biggest}

challenge in biomedical informatics?

Achieving the same status as an established science. That status will attract more young scientists who will shape the future of biomedical informatics. Well-established programmes, developed since the 1980s, have paved the way for the dissemination of biomedical informatics around the world. It will not take long for every major academic institution to develop its own department in this field.

\section{Interview by Virginia Gewin}

$\amalg N$ BRIEF

\title{
Germany seeks applicants
}

Germany's main awarder of science grants, the DFG, is calling for applications for the third phase of its Excellence Initiative, a programme aimed at promoting top research and raising the calibre of German universities and research institutions.

This phase will award some $€ 2.7$ billion (US $\$ 3.8$ billion) in research funding to German universities and institutions; the funding is part of an overall $€ 18$-billion investment in science and education approved in June, the largest such single amount in Germany's post-war history (see http://tinyurl.com/1768c6). Awards will start in 2012 and will run for five years.

\section{UK bioscience boost}

Sixteen new bioscience fellowships worth up to $£ 1.7$ million (US $\$ 2.8$ million) each have been created by the United Kingdom's Biotechnology and Biological Sciences Research Council (BBSRC).

Eight of the fellowships have been awarded to early-career researchers, and five Research Development Fellowships and a Professorial Fellowship will support established scientists. The awards also include the BBSRC's first Industrial Impact Fellowship, under which a pharmaceutical researcher will work in an academic research lab, and a new Diamond Fellowship, to be based near the national synchrotron facility near Harwell.

The fellowships will run for between three and five years.

\section{Stimulus for US science}

\section{A lack of funding}

Times are tough for many principal investigators in Canada. Our lab is one of several to be turned down for a major operating grant recently. According to our rejection letter, our grant application was among the $83 \%$ that were turned down for funding. Of course, many research projects go unfunded - in Canada and elsewhere - not because they lack excellence and merit, but because resources are scarce or the government's commitment is insufficient, especially in this dire economic climate. Nonetheless, I fear that, as a young investigator starting my own research programme, I am not a top priority for reviewers at the Canadian Institutes of Health Research.

Moreover, restructuring of priorities at the Alberta Heritage Foundation for Medical Research - the province's main supporter of health-science research - has left many labs at my institute without operating funds for the next year or more.

For the first time, I hear hushed talk among senior staff that well-established principal investigators may have to let lab members go, or even shut their doors, in the coming months. In our lab, some of us may have to move on if we can't soon acquire fellowships and other research grants to cover our salaries.

I worry that Canada's provincial and federal governments are sending the wrong message to young researchers.

And that means a more tenuous future for young health scientists in Canada myself included.

Julia Boughner is a postdoc in evolutionary developmental biology at the University of Calgary, Canada.
In the United States, up to \$85 million in federal stimulus funds is up for grabs by early-career researchers at academic institutions and Department of Energy national labs. US energy secretary Steven Chu announced the awards, to be made in early 2010, in mid-July. They will support at least 50 researchers for five years apiece.

Eligible researchers must be tenuretrack assistant professors who have earned a PhD within the past 10 years. Each university award will be for at least $\$ 150,000$ per year, and the national lab awards will be for at least $\$ 500,000$ per year. Research topics are limited to scientific computing research; biological and environmental research; basic-energy sciences; fusion-energy sciences; highenergy physics; and nuclear physics. 